\title{
THE EFFECT OF INNOVATION CAPABILITY ON FIRM PERFORMANCE: EVIDENCE FROM THE SOFTWARE SECTOR IN PAKISTAN
}

\author{
Shabbar Hussain \\ The Millennium University College, Islamabad, Pakistan
}

Afshan Rehman

Faculty of Management Sciences, International Islamic University, Islamabad, Pakistan

Afsheen Jalil

Faculty of Management Sciences, International Islamic University, Islamabad, Pakistan

\section{Mehreen Arif}

Department of Management Sciences, Capital University of Science \& Technology, Islamabad, Pakistan

\section{Masood Hassan*}

PhD Scholar, Institute of Business Management (IoBM), Karachi, Pakistan

*Corresponding Author

\begin{abstract}
The development of the software industry is an archetype of how economic liberalization combined with an entrepreneurial spirit can build an industry that today contributes to the GDP of a developing country like Pakistan. Within the software industry, the pace of technological change fosters a particular sense of urgency surrounding the need to innovate. This drives innovation toward the heart of the business strategies of software organizations. The current study develops a structure regarding factors that influence the performance of firms such as innovation capability, technological innovations, and non-technological innovation. The focus of the study is to determine the effect of a multi-dimensional variable such as innovation capability on firm performance by taking technological innovation and non-technological innovation as the mediators. 241 software firms that are working in different cities of Pakistan contributed to this survey. The study adopted a quantitative approach and collected 275 questionnaires from software firm employees in Pakistan using a random sampling technique. Findings revealed that innovation capability has a significant positive relation with firm performance. Additionally, both technological innovation and non-
\end{abstract}


technological innovation acts as a mediator between them and the implementation of both types of innovation is necessary to enhance firm performance.

JEL Code: L25, O31, D24

Key Words: Innovation Capability, Absorptive Capacity, Technological Orientation, Market Orientation, Technological Innovation, Non-technological Innovation, Firm Performance

Cite this Article: Shabbar Hussain, Afshan Rehman, Afsheen Jalil, Mehreen Arif, Masood Hassan, The Effect of Innovation Capability on Firm Performance: Evidence from the Software Sector in Pakistan, International Journal of Management, 11(12), 2020, pp 3480-3490. https://iaeme.com/Home/issue/IJM?Volume=11\&Issue=12

\section{INTRODUCTION}

The software sector is a high technology sector having characteristics like a high rate of innovations, shorter technology life cycles, product value decreasing rapidly that results in shorter product life cycles, global market, high knowledge intensity, and intensive competition worldwide (Nambisan, 2002). Many past studies concluded that to survive in the global marketplace, the main source is innovation that contributes to a firm's competitive advantage. Firms competing in such dynamic and ever-changing environments are focusing on innovation as they consider it as a key element of competitiveness. In view of Laforet (2011), innovation is only possible if the firm has the capability to innovate. The firm's capability to innovate is the most crucial factor for competitive advantage in highly turbulent market conditions. Innovation capability leads the organization to develop innovations continuously to respond to the changing market environment and is embedded with all the strategies, systems, and structures that support innovation in an organization (Rajapathirana \& Hui, 2018). In the current study, innovation capability is examined as a multi-dimensional variable and its dimensions include absorptive capacity and strategic orientation (technological orientation and market orientation).

Innovation capability is defined as a firm's ability to identify new ideas and transform them into new/improved products, services, or processes that benefit the firm. Innovation capability refers to organizations' ability to exploit novel products, new processes, and accomplish significant technical and management achievements. Absorptive capacity the firm's ability to value, assimilate, and apply new knowledge for improving organizational learning. Technological orientation means integrating new technologies rapidly or valuing the new technological means of accessing information. Market orientation is an approach to business that prioritizes identifying the needs and desires of consumers and creating products and services that satisfy them. A market-orientated organization looks at the market and its target audience first, before any production or sales activities take place, to learn what potential customers want from organizations. The product or service offering is therefore created with the customer in mind, resulting in a truly customer-first approach. Firm performance (learning, growth, and innovation performance) contributes to the development of the firm. These three factors make a firm capable to progress in the competitive environment and are more efficient than their competitors at capturing ideas and converting them into products.

Rajapathirana and Hui (2018) explored the relationship between innovation capability, innovation type, and the different aspects of firm performance including innovation, market, and financial performance based on an empirical study covering the insurance industry in Sri Lanka. The results confirmed that the relationship between innovation capabilities and innovation efforts and firm performance is significant and strong. The results of this study could 
lead to effective management of innovation capability which helps to deliver more effective innovation outcomes to generate better performance and it would benefit the management of the insurance companies.

The various sectors of different countries are discussed by scholars, but the software/IT sector of Pakistan has received no attention in the literature that examined the link between innovation capability and firm performance. This creates a research gap. There is also a need to analyze the positive mediators in the existing model. Another reason for selecting the software/IT sector is the lack of such studies that highlight the value of the software sector.

The summed-up objective of the study is to structure and test an integrated model of innovation capability and its impact on firm performance, with the mediating aspect of technological innovation and non-technological innovation, in the Software/IT industry of Pakistan. The current study includes the support of the resource-based view (RBV) theory that is used to propose the research framework. The findings of this research will not only contribute to the literature on innovation capabilities, technological innovation, non-technological innovation, and firm performance but will also provide some future guidelines for researchers to uncover the critical areas that directly impact the performance of the firm. This study can help to boost or encourage firms to perform innovatively if they want to have higher performance in the industry. This would also have a contribution in the field of innovation and technology through giving information about the outcomes of using capabilities for firm improvement.

\section{LITERATURE REVIEW}

Absorptive capacity is related to attaining new knowledge from the external or internal environment, merge it with the previous knowledge, and utilize it to do innovations. It is the central element of knowledge management and innovation that leads to the capability to innovate. Knowledge as a resource is a key element for absorptive capacity that maintains the competitive capability and firm innovation (Lau \& Lo, 2013). There are two main parts of absorptive capacity - namely prior knowledge and intensity of effort. Previous knowledge serves as a platform for the accumulation of new knowledge in the future. The intensity of efforts includes the effort and the time of firm individuals to enhance the absorptive capacity. Absorptive capacity acts as a dimension of innovation capability, as it enables a firm to acquire new knowledge, combine it with the previous knowledge and use it in the innovation process that may include technological and non-technological innovations.

Technological orientation is related to the adaption of new technologies. Technological changes and the commercialization of new technologies results in doing innovation. So, technological development is possible if the firm has the required capability. Technologically oriented firms devote their resources to acquiring new and advanced technologies and developing new processes, products, and services, although, the rate of technological changes within an industry might affect their technological adoption and/or development (Han et al., 2008). Innovative firms have a strong technological orientation. Technological orientation enables the firm to be able to survive in a competitive environment as it insists firms actively adopt new technologies for operating procedures and products (Han et al., 2008).

Market orientation is somehow connected with the innovation capability of a firm that's why treated as its dimension. Market orientation is an important market-based asset as firms better understand the marketing environment, customers, and competitors. Market orientation is an important resource for product innovation, as it provides market knowledge about customer needs and expectations (Yi et al., 2018). Therefore it can contribute to high firm performance. Market orientation is positively associated with new product development (Akman \& Yilmaz, 2008). Market orientation means being responsive to innovative marketing 
programs and innovative strategies to changing customer needs. Therefore, market orientation can be seen as continual innovative behavior. Market orientation means being better and different from competitors, also this is usually carried out with the aid of innovation (Baker \& Sinkula, 2007).

The innovation capability can be seen as an overall capability encompassing the ability to absorb, adapt, and transform a given technology into specific management, operations, and transaction routines that can lead one firm to innovation. Increasing a company's ability to innovate means developing the right framework conditions to achieve innovation goals (Baker $\&$ Sinkula, 2007). This has measurable advantages: Companies can develop future strategies that are based on the cultural strengths of business units. This allows strategies to be implemented more efficiently. Firms must merge their organizational policies with innovation capabilities to create and commercialize new services and products. Innovation capability results in technological and non-technological innovation that promotes firms' performance. Based on the literature, the proposed hypotheses are:

\section{H1: Innovation Capability has a significant positive relation with Technological Innovation}

H2: Innovation Capability has a significant positive relation with Non-Technological Innovation

To exist and to thrive, every firm must have some specific capabilities. Innovation capability is an essential prerequisite for efficient idea management and innovation management, as well as for the implementation of disruptive innovations. The innovation process can be slow and cumbersome when a company's ability to innovate is low (Rajapathirana \& Hui, 2018). However, the same process can be extremely efficient if the company is highly innovative. There are many studies on innovation capability aiming at developing the concept itself, as well as trying to identify the capabilities needed that allow the firm to innovate. In this study, firm performance is measured using two dimensions such as innovation performance and learning and growth performance. Innovation performance upgrades the position of the firm through a process-based advantage that with time increases the efficiency of innovation in the firm. Better innovation capability results in better firm performance as past studies conclude that a positive relation exists between innovation capability and firm performance (Rajapathirana \& Hui, 2018; Basuki et al., 2020). Therefore, the proposed hypothesis is

\section{H3: Innovation capability has a significant positive association with firm performance.}

To improve firm performance several studies have found the mediating impact of innovation (Uzkurt et al., 2013). Mediating effects of two types of innovations such as technological and non-technological innovation between innovation capability and firm performance are investigated in this study. Technological innovations including product innovation and process innovation are taken as a mediator in past studies (Markovic \& Bagherzadeh, 2018). Non-technological innovation including organizational innovation also played the role of mediator in previous studies (Prange \& Carlos, 2017). Firms adopt product, organizational, and process innovation for satisfying their customers and for competing with other firms. This study is supported by empirical literature that innovation can improve firm performance. Innovation capabilities facilitate innovation which eventually enhances the overall performance of the firm. Different firms have different levels of innovation capabilities. The growth of the firms is positively related to the formation of innovations. Therefore, proposed hypotheses are 


\section{H4: Technological innovation acts as a mediator between innovation capability and firm performance}

\section{H5: Non-Technological innovation acts as a mediator between innovation capability and firm performance}

Technological innovations include product and process innovations. Exploiting new ideas leads to product innovation and provides customers with a variety of products. Introducing new products or modifying the existing ones to fulfill customer expectations is known as product innovation (Han et al., 2008). Product innovation is defined as the development and market introduction of a new, redesigned, or substantially improved good or service. The main objective of product innovation is to attract new customers. Product innovation and the developments that flow from it enable companies to differentiate themselves in the marketplace. Product innovation opens the door to increased brand equity, faster technology adoption rates, larger returns, and an environment primed for further innovation (Uzkurt et al., 2013).

Process innovation is a new or significantly improved way of doing things in a business that typically increases production levels and decreases costs. Process innovation might come in the form of new processes or techniques, new equipment, or software. Process innovation is the application or introduction of new technology or method for doing something that helps an organization remain competitive and meet customer demands (Uzkurt et al., 2013). Process innovation happens when an organization solves an existing problem or performs an existing business process in a radically different way that generates something highly beneficial to those who perform the process, those who rely on the process or both. The stages of process innovation are novel ideas, idea transformation, idea diffusion, idea formulation, and identification of new opportunities and customer needs. Many researchers concluded that process innovation and firm performance are positively associated with each other (Hassan et al., 2013). Therefore, the proposed hypothesis is:

\section{H6: Technological innovation has a positive relation with Firm performance}

Non-technological innovation is defined as the introduction of new organizational methods or the introduction of new marketing methods. In this study, only organizational innovation is included. Organizational innovation can be defined as the introduction of something new (an idea, product, service, technology, process, and strategy) to an organization (Laforet, 2011). If firms' organizational innovation capability, then it has a direct and strong impact on performance. Organizational innovation is understood to encompass processes that lead to the establishment or adoption of new production and management models, not only for production but also for tangible and intangible resources. The organizational innovation concept is part of the concept of innovation and development and accentuates new ideas and the propensity for change within organizations. Organizational innovation can improve workplace satisfaction/productivity and/or reduce administrative/transaction costs, which, in turn, lead to higher business performance (Prange \& Carlos, 2017). Organizational innovation influences the company's performance through improving quality of work, information exchange, the capacity for learning, and the use of new knowledge and technologies. Therefore, theoretically, organizational innovation will enhance the performance of firms. Organizational innovation is helpful in increasing the efficiency of the business (Prange \& Carlos, 2017). Previous studies showed that there is a positive link between organizational innovation and performance. Therefore, the proposed hypothesis is

\section{H7: Non-technological Innovation is directly associated with Firm performance}

There exists a significant relation between technological innovation and non-technological innovation. Past studies examined the relationship between technological innovation and 
organizational innovation by highlighting that technological innovation drives organizational changes (Danneels, 2002). Balanced implementation of technological innovations and nontechnological innovations are more effective in enhancing and preserving the performance of the firm rather than implementing them alone (Basuki et al., 2020). Firms that are not able to restrict the competitive forces by their non-technological innovations are also not able to create appropriate value while having capabilities in technological innovation. Interaction between technological innovation and non-technological innovation enables the firm to succeed by improving its performance. Therefore, the proposed hypothesis is

\section{H8: Technological innovation has a significant positive relation with non-technological innovation}

The conceptual framework of this study is depicted in Figure 1.

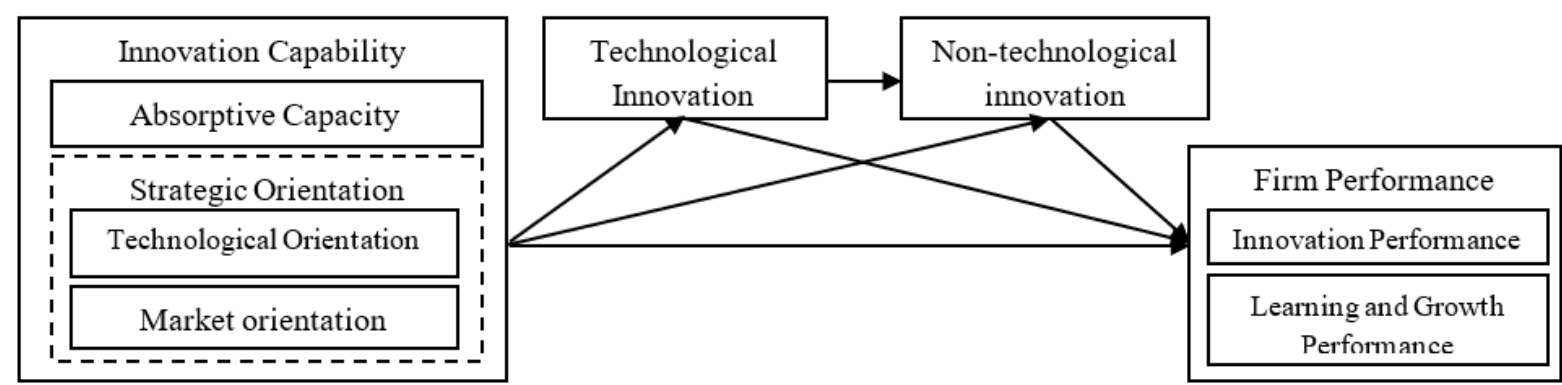

Figure 1 Research Model

\section{METHODOLOGY}

This is quantitative field research where data was collected through a survey-based methodology based on which empirical analysis of the research model was carried out. The population for the proposed study includes employees working in different software firms in Pakistan. To fill the survey, the researchers visited software organizations by using reference. For this purpose, a hard copy of the questionnaire was used. Questionnaires were filled by software managers, Web developers, front-end developers, etc. An online link was also generated and most of the responses were collected by using an online link. For this purpose, Facebook and the LinkedIn app were used to search the professionals working in software companies of Pakistan. Different employees were also contacted through electronic email. About 350 questionnaires were randomly distributed among the employees of software firms. Out of 350 questionnaires, only 310 were returned. The answer rate of the survey was $88.57 \%$. Thirty-five questionnaires that had missing data were ignored. In the end, the sample size was 275.

\subsection{Measurement}

All the variables included in this study were measured based on seven points Likert scale from "1=Strongly Disagree to 7=Strongly Agree". IBM SPSS statistics 20 was used for evaluating the data.

\subsection{Innovation Capability}

Innovation capability was measured by using dimensions such as absorptive capacity, technological orientation, and market orientation. Absorptive capacity consists of a fivequestion measure. Five items related to absorptive capacity were measured by using the questions developed by Kotabe et al. (2011). Technological orientation consists of a five- 
question measure. Market orientation consists of a twelve-question measure. Both variables were measured by using the construct developed and validated by Akman and Yilmaz (2008). The reliability of innovation capability including its dimensions is .906 .

\subsection{Technological Innovation and Non-Technological Innovation}

Technological innovations and non-technological innovations were measured using the questions developed by Ahu (2015). The reliability of technological innovation is .757 and the reliability of non-technological innovation is .625 .

\subsubsection{Firm Performance}

Innovation performance and firm learning and growth performance are the two dimensions of firm performance. Firm innovation performance was measured by using the questions developed by Faruk and Gary (2015). And firm learning and growth performance was measured using the questions developed by Ahu (2015). The reliability of firm performance including its dimensions is .886.

\section{RESULTS}

Statistics provide techniques for collecting the data and sorting it. Descriptive statistics are used to describe the basic features of the data in a study. They provide simple summaries about the sample and the measures. The correlation coefficient is a statistical measure of the strength of the relationship between the relative movements of two variables. Correlation is a bivariate analysis that measures the strength of association between two variables and the direction of the relationship (whether they are positively or negatively correlated to each other). Results related to correlation analysis and descriptive statistics are shown in Table 1.

Table 1 Descriptive statistics and Correlation Analysis

\begin{tabular}{|l|c|c|c|c|c|c|}
\hline & Mean & SD & IC & TI & NI & FP \\
\hline $\begin{array}{l}\text { Innovation } \\
\text { Capability (IC) }\end{array}$ & 5.8643 & .65104 & 1 & & & \\
\hline $\begin{array}{l}\text { Technological } \\
\text { innovation (TI) }\end{array}$ & 5.7042 & .86298 & .62 & 1 & & \\
\hline $\begin{array}{l}\text { Non Technological } \\
\text { innovation (NI) }\end{array}$ & 5.1964 & 1.31859 & .43 & .40 & 1 & \\
\hline $\begin{array}{l}\text { Firm Performance } \\
\text { (FP) }\end{array}$ & 5.4137 & .96270 & .59 & .56 & .51 & 1 \\
\hline
\end{tabular}

Table 1 shows the (i) mean, which implies average and it is the sum of a set of data divided by the number of data. Mean can prove to be an effective tool when comparing different sets of data (ii) standard deviation which is a statistic that measures the dispersion of a dataset relative to its mean and supports the correlation between the variables. As shown in Table 1, correlation analysis supports the correlation between the variables. Results show that IC and TI have a positive correlation with each other with a strong significant correlation value of .62. This shows that if innovation capability enhances, then technological innovation also enhances. The correlation value between IC and NI was .43. This shows that if innovation capability increases, then non-technological innovation also increases. IC is positively related to FP with a correlation value of .59. It shows that if the firm has innovation capability, then it improves firm performance. The correlation value between TI and NI is .40. This shows that technological innovation has a direct relation with non-technological innovation. If one increases, then the other also increases. Results also prove that TI is positively related to FP with a significant correlation value of .56. It shows that if technological innovation rises, then firm performance also rises. The correlation value between NI and FP is .51, which is a positive 
and significant value. This shows that if non-technological innovation increases, then there will be an increase in firm performance.

Table 2 Model Summary

\begin{tabular}{|c|c|c|c|c|}
\hline Model & $\mathbf{R}$ & $\mathbf{R}^{\mathbf{2}}$ & Adjusted R $^{\mathbf{2}}$ & Std. Error of the Estimate \\
\hline 1 & $.598^{\mathrm{a}}$ & .358 & .355 & .77306 \\
\hline
\end{tabular}

Table 2 provides the values of $R, R^{2}$, and Adjusted $R^{2}$. Simple correlation is represented by the value of $R . R^{2}$ is a statistical measure that represents the proportion of the variance for a dependent variable that's explained by an independent variable or variables in a regression model. Adjusted $\mathrm{R}^{2}$ takes into account the number of independent variables used for predicting the target variable. In doing so, we can determine whether adding new variables to the model actually increases the model fit. In this study, $\mathrm{R}=.5 .89$, which indicates the high degree of correlation between IC and FP. The value of $\mathrm{R}^{2}=.358$ specifies that $35.8 \%$ variation in the dependent variable is caused by the independent variable and the value of Adjusted $\mathrm{R}^{2}=.355$ specifies that $35.5 \%$ variation in the dependent variable is caused by the independent variable

Table 3 Coefficients

\begin{tabular}{|l|c|c|c|c|c|}
\hline \multirow{2}{*}{ Model } & \multicolumn{2}{|c|}{$\begin{array}{c}\text { Unstandardized } \\
\text { Coefficients }\end{array}$} & Standardized Coefficients & \multirow{2}{*}{ t } & \multirow{2}{*}{ Sig. } \\
\cline { 2 - 6 } & $\mathbf{B}$ & Std. Error & $\boldsymbol{\beta}$ & 541 & 589 \\
\hline \multirow{2}{*}{1 (Constant) } & .229 & .423 & & 12.325 & 000 \\
\hline IC & .884 & .072 & .598 & & \\
\hline a. Dependent Variable: FP
\end{tabular}

Results in Table 3 provide information about the ability of innovation capability to predict firm performance. Value of Sig shows whether innovation capability contributes statistically and significantly to FP. In this case, the value of Sig=.000 indicates that IC is statistically and significantly related to FP. Additionally, values of the B column under unstandardized coefficients can be used to represent the regression equation that is shown below

$$
F P=.229+.884(I C)
$$

The mediator variable determines the relationship between the dependent and the independent variable. In the current study, two mediators were included such as technological innovation and non-technological innovation.

PROCESS v2 16.3 macro tool was used for the evaluation of dual mediation. As this study includes two mediators, therefore, model 6 with two mediators was used according to the model templates for SPSS and SAS. Variables included in the model analysis were $\mathrm{X}=\mathrm{Innovation}$ capability (IC), Y= Firm Performance (FP), M1=Technological Innovation (TI), and M2=nonTechnological innovation (NI). The sample size was 275. Direct effect results of the model analysis are shown in Table 4.

Table 4 Direct effect between variables

\begin{tabular}{|c|c|c|c|c|}
\hline Paths & Effect & P & LLCI & ULCI \\
\hline IC $\rightarrow$ TI & .8337 & .0000 & .7109 & .9565 \\
\hline TI $\rightarrow$ NI & .3296 & .0019 & .1222 & .5371 \\
\hline IC $\rightarrow$ NI & .6080 & .0000 & .3331 & .8830 \\
\hline TI $\rightarrow$ FP & .2876 & .0000 & .1612 & .4141 \\
\hline NI $\rightarrow$ FP & .1985 & .0000 & .1270 & .2700 \\
\hline IC $\rightarrow$ FP & .4691 & .0000 & .2988 & .6395 \\
\hline
\end{tabular}


Table 4 represents the effects between the variables. All the paths have a value of $p<0.05$ and no zero value exists between the lower and upper limits that showed significant relation exists between variables. The indirect effects of the independent variable (IC) on the dependent variable (FP) are shown in Table 5. The model includes three indirect effects of IC on FP as shown below.

Table 5 Indirect Effects

\begin{tabular}{|c|c|c|c|}
\hline & Effect & Boot LLCI & Boot ULCI \\
\hline Total & .4150 & .2932 & .5519 \\
\hline $\mathrm{IC} \rightarrow \mathrm{TI} \rightarrow \mathrm{FP}$ & .2398 & .1292 & .3584 \\
\hline $\mathrm{IC} \rightarrow \mathrm{TI} \rightarrow \mathrm{NI} \rightarrow \mathrm{FP}$ & .0545 & .0152 & .1194 \\
\hline $\mathrm{IC} \rightarrow \mathrm{NI} \rightarrow \mathrm{FP}$ & .1207 & .0553 & .2175 \\
\hline
\end{tabular}

In the case of all indirect paths, no zero was lying between the lower limit and upper limit. If TI is partially implemented as a mediator, then the indirect effect is .2398. If NI is partially implemented as the mediator, then the indirect effect is .1207 but when both TI and NI are implemented as mediators, the indirect effect is .0545. Variation between the values of direct and indirect effect is greater when both $\mathrm{TI}$ and NI are implemented together as compared to when they are implemented partially. This shows the implementation of both types of innovation is necessary to improve FP. Results specify that TI and NI both act as mediators.

\section{CONCLUSION AND LIMITATIONS}

The aim of the study was to find out the multi-dimensional effect of IC on FP with the mediating role of TI and NI. Sample data was collected from software firms of Pakistan through a surveybased methodology to measure the extent to which IC impacts FP with mediating role of TI and NI. The sample data was based on 275 questionnaires that were analyzed. Statistical tests specify the reliability and validity of the variables included in the research model. RBV theory was utilized as a theoretical lens that supported the proposed hypotheses. The findings of the study are in line with RBV theory because all the proposed hypotheses are accepted in the context of Pakistan.

The current study has contributed to the literature as no study outlined the multidimensional effect of innovation capability on firm performance in the Pakistani context. The proposed study has many contributions to the engineering management domain of innovations. Engineering management is the mixture of engineering and business practices that are concerned with the design, development, improvement, and implementation of systems, processes, and models by considering engineering relationships with management tasks such as plan, organize, control, direct and lead the human element in production, marketing, research, and other services. Results revealed TI and NI both are necessary to be implemented as TI is based on engineering practices and NI is based on business practices.

The current study demonstrates that IC enhances FP, therefore the study suggests that technology-based firms must have IC based on their absorptive capacity, technological orientation, and market orientation. This forms the basis of doing TI and NI that consequently enables a firm to maintain its position in the competitive environment.Despite that current research has achieved some important conclusions and insight, results and the finding of the study should be considered with some limitations that provide researchers with new ideas and suggestions, and this practice gives rise to future research work. First, the current study was conducted on the software sector of Pakistan. The sample used in the study was taken from software firms in Pakistan. Therefore, the results are limited to this sample only. The same study can be conducted in other sectors of developing countries where such studies are rare. Second, the proposed study is based on a single sector. 
Data can also be acquired from multiple sectors to improve the validity of the findings Third, control variable such as the gender of the respondent was not considered. This may have affected the results as sample data can be male-biased or female-biased. Future studies can examine the effect of control variables on the outcome. Fourth, this study only includes two mediators and does not include any moderating effect. So, studies are required to examine the effect of IC on FP by considering different constructs as moderators like performance measurement, or the model can be improved by adding other mediators or moderators. Fifth, time restriction was the main limitation of the current study. This may affect the findings of the study because it is a cross-sectional study where data is collected once within 2 months. So, a longitudinal study can be conducted to investigate the effect of IC on FP where data will be collected with specific time intervals. Sixth, only three dimensions of innovation capability were included in this study. Further, innovation capability with other dimensions such as personnel capability, operational capability, and structural capability should be studied to examine the influence of a multi-dimensional variable such as IC on FP.

\section{REFERENCES}

[1] Ahu, T. K. (2015). Effects of innovation types on performance of manufacturing firms in Turkey. World Conference on Technology, Innovation and Entrepreneurship Effects, 195, 1355-1364. https://doi.org/10.1016/j.sbspro.2015.06.322

[2] Akman, G., \& Yilmaz, C. (2008). Innovative capability, innovation strategy and market orientation: An empirical analysis in the Turkish software industry. International Journal of Innovation Management, 12(1), 69-111. https://doi.org/10.1142/S1363919608001923

[3] Baker, W. E., \& Sinkula, J. (2007). Does market orientation facilitate balanced innovation programs? An organizational learning perspective. Journal of Product Innovation Management, 24, 316-334. https://doi.org/10.1111/j.1540-5885.2007.00254.x

[4] Basuki, B., Pulungan, N. A. F., \& Udin, U. D. I. N. (2020). The effect of innovation on price to book value: The role of managerial ownership in Indonesian companies. The Journal of Asian Finance, Economics, and Business, 7(5), 249-258. https://doi.org/10.13106/jafeb.2020.vol7.no5.249

[5] Danneels, E. (2002). The dynamics of product innovation and firm competencies. Strategic Management Journal, 23, 1095-121. https://doi.org/10.1002/smj.275

[6] Faruk, K., \& Gary, S. L. (2015). The impact of strategic innovation management practices on firm innovation performance. Research Journal of Business and Management, 2(3).

[7] Han, H. K., Kim, N., \& Kim, B. (2008). Entry barriers: A dull-, one-, or two-edged sword for incumbents? Unraveling the paradox from a contingency perspective. Journal of Marketing, 65(1), 1-14. https://doi.org/10.1509/jmkg.65.1.1.18133

[8] Hassan, M., Shaukat, S., Nawaz, M., \& Naz, S. (2013). Effects of innovation types on firm performance: An empirical study on Pakistan's manufacturing sector. Pakistan Journal of Commerce and Social Sciences, 7(2), 243 - 262.

https://www.econstor.eu/bitstream/10419/188088/1/pjcss121.pdf

[9] Kotabe, M., Jiang, C. X., \& Murray, J. Y. (2011). Managerial ties, knowledge acquisition, realized absorptive capacity and new product market performance of emerging multinational companies: A case of China. Journal of World Business, 46(2), 166-176. https://doi.org/10.1016/j.jwb.2010.05.005 
[10] Laforet, S. (2011). A framework of organizational innovation and outcomes in SMEs. International Journal of Entrepreneurial Behavior, 17(4), 380-408. https://doi.org/10.1108/13552551111139638

[11] Lau, A. K. W., \& Lo, W. (2013). Absorptive capacity, technological innovation capability, and innovation performance. International Journal of Technology Management, 80(1-2), 107, https://doi.org/10.1504/IJTM.2019.099750

[12] Markovic, S., \& Bagherzadeh, M. (2018). How does the breadth of external stakeholder cocreation influence innovation performance? Analyzing the mediating roles of knowledge sharing and product innovation. Journal of Business Research, 88(3), 173-186. https://doi.org/10.1016/j.jbusres.2018.03.028

[13] Nambisan, S. (2002). Software firm evolution and innovation orientation. Journal of Engineering and Technology Management, 19(2), 141-165. https://doi.org/10.1016/S09234748(02)00007-3

[14] Prange, C., \& Carlos, J. (2017). How personal and organizational drivers impact SME international performance: The mediating role of organizational innovation. International Business Review, 26(6), 1114-1123. https://doi.org/10.1016/j.ibusrev.2017.04.004

[15] Rajapathirana, R. P. J., \& Hui, Y. (2018). Relationship between innovation capability, innovation type, and firm performance. Journal of Innovation \& Knowledge, 3(1), 44-55. https://doi.org/10.1016/j.jik.2017.06.002

[16] Uzkurt, C., Kumar, R., Semih Kimzan, H., \& Eminoglu, G. (2013). Role of innovation in the relationship between organizational culture and firm performance: A study of the banking sector in Turkey. European Journal of Innovation Management, 16(1), 92-117. https://doi.org/10.1108/14601061311292878

[17] Yi, H. T., Han, C. N., \& Cha, Y. B. (2018). The effect of entrepreneurship of SMEs on corporate capabilities, dynamic capability, and technical performances in South Korea. The Journal of Asian Finance, Economics, and Business, 5(4), 135-147. https://doi.org/10.13106/jafeb.2018.vol5.no4.135 